OPEN ACCESS

Edited by:

Toshi Nagata,

The University of Tokyo, Japan

Reviewed by:

Pamela E. Rossel,

GFZ German Research Centre

for Geosciences, Helmholtz Association of German Research

Centres (HZ), Germany

Patrick J. Neale,

Smithsonian Environmental Research

Center (SI), United States

${ }^{*}$ Correspondence:

Patricia M. Medeiros

medeiros@uga.edu

Specialty section:

This article was submitted to Marine Biogeochemistry,

a section of the journal

Frontiers in Marine Science

Received: 22 September 2021 Accepted: 18 November 2021 Published: 08 December 2021

Citation:

Martineac RP, Vorobev AV, Moran MA and Medeiros PM (2021) Assessing the Contribution of Seasonality, Tides, and Microbial Processing to Dissolved Organic Matter Composition Variability in a

Southeastern U.S. Estuary.

Front. Mar. Sci. 8:781580.

doi: 10.3389/fmars.2021.781580

\section{Assessing the Contribution of Seasonality, Tides, and Microbial Processing to Dissolved Organic Matter Composition Variability in a Southeastern U.S. Estuary}

\author{
Rachel P. Martineac ${ }^{1}$, Alexey V. Vorobev' ${ }^{2}$, Mary Ann Moran ${ }^{1}$ and Patricia M. Medeiros ${ }^{\text {* }}$ \\ 'Department of Marine Sciences, University of Georgia, Athens, GA, United States, ${ }^{2}$ INSERM U932, Institut Curie, \\ PSL University, Paris, France
}

Uncovering which biogeochemical processes have a critical role controlling dissolved organic matter (DOM) compositional changes in complex estuarine environments remains a challenge. In this context, the aim of this study is to characterize the dominant patterns of variability modifying the DOM composition in an estuary off the Southeastern U.S. We collected water samples during three seasons (July and October 2014 and April 2015) at both high and low tides and conducted short- (1 day) and long-term (60 days) dark incubations. Samples were analyzed for bulk DOC concentration, and optical (CDOM) and molecular (FT-ICR MS) compositions and bacterial cells were collected for metatranscriptomics. Results show that the dominant pattern of variability in DOM composition occurs at seasonal scales, likely associated with the seasonality of river discharge. After seasonal variations, long-term biodegradation was found to be comparatively more important in the fall, while tidal variability was the second most important factor correlated to DOM composition in spring, when the freshwater content in the estuary was high. Over shorter time scales, however, the influence of microbial processing was small. Microbial data revealed a similar pattern, with variability in gene expression occurring primarily at the seasonal scale and tidal influence being of secondary importance. Our analyses suggest that future changes in the seasonal delivery of freshwater to this system have the potential to significantly impact DOM composition. Changes in residence time may also be important, helping control the relative contribution of tides and long-term biodegradation to DOM compositional changes in the estuary.

Keywords: dissolved organic matter, DOM composition, microbial degradation, FT-ICR MS, marsh-dominated estuary, GCE-LTER, Southeastern U.S.

\section{INTRODUCTION}

The world ocean is one of the largest reservoirs of organic matter on Earth, containing approximately the same amount of carbon as atmospheric carbon dioxide (Hedges, 1992; Walther, 2013). The marine dissolved organic matter (DOM) pool is estimated to be $662 \mathrm{Pg} C$ (Hansell et al., 2009), and comprises a major part of the carbon budget in marine ecosystems. Marine 
DOM composition is diverse, containing between tens to hundreds of thousands of distinct organic molecules (Kim et al., 2003), and a wide range of lability depending on the variety of molecular compositions in different environments (e.g., Meyer et al., 1987; Moran and Hodson, 1994; Amon and Benner, 1996). Additionally, DOM composition and quality are affected by the inputs of many different sources as well as the complex interactions of abiotic and biotic processes (Sholkovitz, 1976; Kieber et al., 1990; Miller and Moran, 1997; Hernes and Benner, 2003).

Coastal ecosystems are specifically important to our understanding of DOM composition and transformation due to the combination of carbon inputs from both marine and terrestrial sources (Hedges et al., 1997). Researching DOM composition in estuaries can elucidate processes involved in organic carbon production (Bianchi, 2006) and sequestration (Watanabe and Kuwae, 2015) in these areas. By uncovering how estuaries process DOM, we gain insight into fluxes of dissolved organic carbon (DOC) to the ocean and fluxes of $\mathrm{CO}_{2}$ to the atmosphere, especially because these regions can be both carbon sources and sinks (Bauer et al., 2013; Noriega and Araujo, 2014; Canuel and Hardison, 2016). Therefore, determining the biogeochemical processes that affect DOM composition is important to our understanding of carbon cycling in estuaries.

Exploring the differences between major DOM inputs to estuaries provides insight into which biogeochemical factors are most important in considering transformations in a given region. For instance, seasonal changes in river discharge, as is typical in the Southeast U.S., have been shown to enhance the export of terrigenous DOM to estuaries (e.g., Medeiros et al., 2017b; Letourneau and Medeiros, 2019; Osburn et al., 2019). Tides also have an impact on the DOM composition in estuaries as sources of DOM shift on short-time scales (Tzortziou et al., 2008; Seidel et al., 2014). Substantial transformations of DOM composition due to bacterial consumption have also been observed in Southeastern U.S. coastal waters (Moran and Hodson, 1989, 1994; Miller and Moran, 1997; Moran et al., 1999; Medeiros et al., 2015a, 2017b; Vorobev et al., 2018; Letourneau et al., 2021). These environmental complexities make quantifying the influence of sources and biogeochemical processes affecting DOM composition in estuaries difficult. Previous studies have found the driving control of DOM compositional change in many estuarine systems to be water mixing across a marinefreshwater gradient (Sleighter and Hatcher, 2008; Medeiros et al., 2015a; Osterholz et al., 2016). Medeiros et al. (2017b) described how DOM from different sources may influence the patterns of transformation at the molecular level due to biodegradation. Additionally, studies have investigated the microbial community composition to gain insight into their role modifying the molecular composition of the DOM pool (Osterholz et al., 2016, 2018; Vorobev et al., 2018).

This study aims to build upon prior research by characterizing the most important patterns of variability modifying the DOM composition in a typical estuary of the Southeastern U.S. over three seasons. In this context, we used dark incubations on short (1 day) and long (60 days) timescales to compare biodegradation of DOM to seasonal and tidally-driven changes in DOM composition using bulk, optical and molecular chemical techniques coupled with metatranscriptomic data to assess composition variability at the molecular level.

\section{MATERIALS AND METHODS}

\section{Sample Collection and Incubation}

Surface water samples were collected in three seasons (July and October 2014, and April 2015) at Marsh Landing in Doboy Sound, Georgia, United States (Figure 1). Temperatures at the time of collection were $\sim 30,26$, and $21.5^{\circ} \mathrm{C}$ for July, October and April, respectively. Doboy Sound is characterized by marine influence augmented with terrestrial inputs from the Altamaha River (Medeiros et al., 2015a), the dominant source of freshwater to the area (Schaefer and Alber, 2007). This study location was selected due to extensive prior research on the gene expression from ambient microbial communities (e.g., Poretsky et al., 2005, 2010; Gifford et al., 2011, 2013; Hollibaugh et al., 2011, 2013) coupled with characterization of the DOM pool (Medeiros et al., 2015a, 2017b; Letourneau et al., 2021). Samples from July and October 2014 analyzed here have been previously described in Vorobev et al. (2018).

In the three seasons, water samples were collected at high and low tide into triplicate $20 \mathrm{~L}$ acid-washed carboys for initial (T0), and short-term (1 day; T1) dark incubations. Long-term (60 days; T60) dark incubations were also pursued for high tide samples in October 2014 and April 2015. Triplicate T0 samples were processed immediately, while triplicate $\mathrm{T} 1$ water containers were wrapped in black plastic and immediately returned to Doboy Sound for a 1-day ( $24 \mathrm{~h}$ ) incubation before processing. Samples were processed by filtering $3 \mathrm{~L}$ through $3 \mu \mathrm{m}$ poresize filters (Capsule Pleated Versapor Membrane filters; Pall Life Sciences) to remove eukaryotic cells, then through $0.2 \mu \mathrm{m}$ pore-size filters (Supor polyethersulfone filter; Pall Life Sciences) to collect bacterial cells. The $0.2 \mu \mathrm{m}$ filters were placed in Whirl-Pak plastic bags and flash-frozen in liquid nitrogen for metatranscriptomic analysis, which was conducted on July and October samples (Vorobev et al., 2018). Sample filtrates were collected for bulk DOC concentration, and optical (CDOM) and molecular (FT-ICR MS) composition analyses. Aliquots for DOC and CDOM analyses were collected and stored frozen $\left(-20^{\circ} \mathrm{C}\right)$ and refrigerated $\left(4^{\circ} \mathrm{C}\right)$, respectively. The remaining filtrates $(2$ L) were acidified to $\mathrm{pH} 2$ (using $\mathrm{HCl}$ ), and DOM was extracted with solid phase extraction (SPE) using styrene divinyl benzene polymer (Agilent Bond Elut PPL) as described in Letourneau and Medeiros (2019).

For the long-term incubations, $4 \mathrm{~L}$ water samples were immediately transported to the laboratory, where inorganic nutrients $\left(20 \mu \mathrm{M} \mathrm{Na} \mathrm{PO}_{4}\right.$ and $\left.50 \mu \mathrm{M} \mathrm{NH}{ }_{4} \mathrm{Cl}\right)$ were added to the raw seawater to alleviate inorganic nutrient limitation on bacterial carbon processing. Samples were then filtered through pre-combusted $\left(5 \mathrm{~h}\right.$ at $\left.450^{\circ} \mathrm{C}\right) 2.7 \mu \mathrm{m}$ pore size filters $(\mathrm{GF} / \mathrm{D}$; Whatman) before dark-incubating in triplicate for 60 days at $24^{\circ} \mathrm{C}$. After incubations were complete, samples were filtered through Pall Supor membrane filters $(0.2 \mu \mathrm{m})$ and filtrates were collected for DOC, CDOM and FT-ICR MS analyses as described above. 

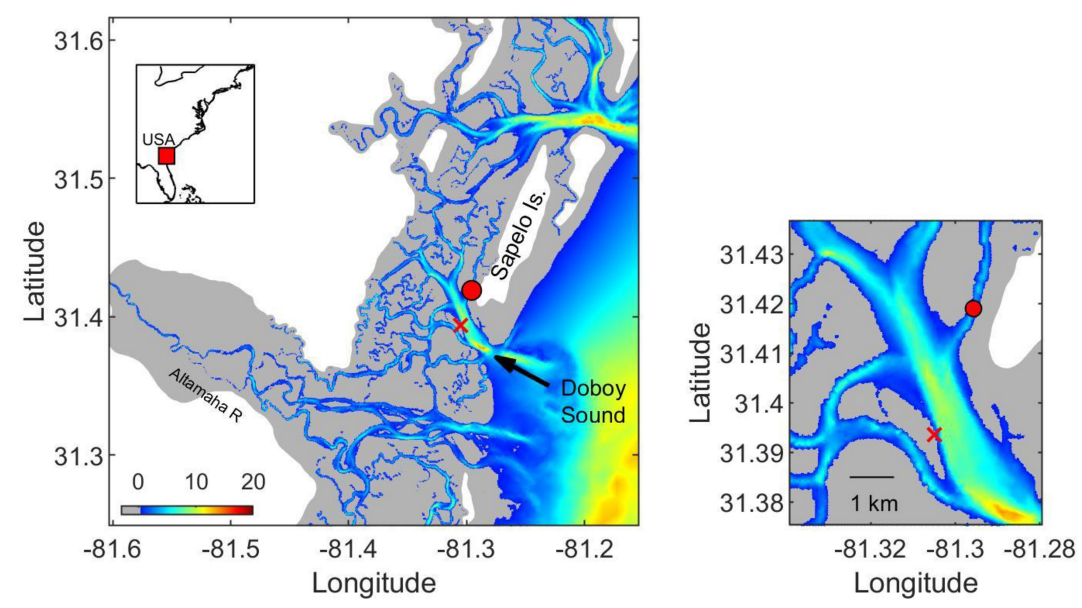

FIGURE 1 | (left) Sampling location in Doboy Sound, GA (red circle). Salt marshes and uplands are shown in gray and white, respectively. Colors indicate bottom topography in meters. Location of oceanographic mooring GCE6, where salinity time series was obtained (see Figure 8), is shown by red cross. (right) Region around sampling site is shown in detail.

\section{Bulk Dissolved Organic Carbon and Chromophoric Dissolved Organic Matter}

Dissolved organic carbon concentrations from T0, T1, and T60 water samples and SPE-DOC extracts (dried and resuspended in ultrapure water) were measured using a Shimadzu TOC$\mathrm{L}_{C P H}$ analyzer with potassium hydrogen phthalate as a standard. Milli-Q water blanks were tested before sample analysis and throughout instrument use. Accuracy and precision were tested against deep-sea reference material (Hansell, 2005) and were better than 5\%. SPE extraction efficiency across all samples (the SPE extract vs. DOC concentration in the original sample) was $71 \% \pm 4 \%$ of the DOC. Biodegradation of DOC (\%) was determined as

$$
\frac{\text { DOC }_{T_{0}}-\text { DOC }_{T_{\text {end }}}}{\text { DOC }_{T_{0}}} \times 100
$$

where $\mathrm{DOC}_{T 0}$ is the concentration of DOC in the samples before incubations, and $\mathrm{DOC}_{\text {Tend }}$ is the concentration of DOC in samples after either 1- or 60-day incubations.

Absorbance measurements of water samples for CDOM were taken at room temperature using an Agilent 8453 UVvisible spectrophotometer with a $1 \mathrm{~cm}$ quartz cuvette. Blank calibrations using Milli-Q water were performed prior to sample measurement to achieve a baseline background level. Absorbance was measured from wavelengths 190 to $1,100 \mathrm{~nm}$ and was converted to absorption coefficients as in D'Sa et al. (1999). The ratio of absorption coefficients at $\lambda=250 \mathrm{~nm}$ to $\lambda=365 \mathrm{~nm}$ $\left[a_{g}(250): a_{g}(365)\right]$ was calculated for each sample. The CDOM absorption ratio is inversely correlated to DOM aromaticity and molecular weight (Peuravuori and Pihlaja, 1997). The spectral slope $\left(S_{275-295}\right)$ was calculated between 275 and $295 \mathrm{~nm}$ as in Helms et al. (2008) and has been shown to be correlated negatively with terrigenous DOM (Fichot and Benner, 2012).

\section{Molecular Analysis Using FT-ICR MS}

The molecular composition of DOM extracts $\left(200 \mathrm{mg} \mathrm{C} \mathrm{L}^{-1}\right.$ in methanol) was analyzed using a $9.4 \mathrm{~T}$ Fourier transform ion cyclotron resonance mass spectrometer (FT-ICR MS) at the National High Magnetic Field Laboratory (NHMFL, Florida State University, Tallahassee, FL, United States) with electrospray ionization (ESI; negative mode). Samples were processed as described in Vorobev et al. (2018). Briefly, each $m / z$ spectrum was internally calibrated with respect to an abundant homologous alkylation series whose members differ in mass by integer multiples of $14.01565 \mathrm{Da}$ (mass of a $\mathrm{CH}_{2}$ unit) confirmed by isotopic fine structure (Savory et al., 2011), achieving a mass error of $<0.5 \mathrm{ppm}$. Molecular formulae were assigned for masses in the range of 150 and $750 \mathrm{Da}$ by applying the following restrictions: ${ }^{12} \mathrm{C}_{1-100}{ }^{1} \mathrm{H}_{1-200} \mathrm{O}_{1-25}{ }^{14} \mathrm{~N}_{0-4} \mathrm{~S}_{0-2}$, where the subscripts indicate the range in the number of atoms considered when assigning formulae. Molecular formulae assignment was performed by Kendrick mass defect analysis (Wu et al., 2004) using PetroOrg software (Corilo, 2014) as in Letourneau and Medeiros (2019). Compounds with a signalto-noise ratio smaller than 6 were discarded from the analysis to eliminate inter-sample variability based on peaks that were close to the detection limit. The peak intensity of each molecular formula was normalized by the sum peak intensities of the total identified peaks in each sample.

\section{Microbial Analysis}

Bioinformatic processing via differential gene expression (DGE) was performed using the DESeq2 package in $\mathrm{R}$ (Love et al., 2014). Genes were mapped on marine microbial genomic databases (SILVA database) $)^{1}$ to identify taxa associated with gene expression. Separately, principal component (PC) analysis was performed using the normalized gene expression data from DEseq2 to capture patterns of variability in the microbial

\footnotetext{
${ }^{1}$ www.arb-silva.de
} 
samples. A detailed description of the microbial data processing is presented in Vorobev et al. (2018).

\section{Ancillary Data}

River discharge at the Altamaha River is routinely measured by the U.S. Geological Survey (USGS) at Doctortown, GA. ${ }^{2}$ Temperature and salinity time series at multiple locations in the estuary are available as part of the Georgia Coastal Ecosystem Long Term Ecological Research (GCE-LTER) program. ${ }^{3}$ Longterm monitoring site GCE6 is located about $3 \mathrm{~km}$ from our sampling site (Figure 1).

\section{RESULTS}

The estuary around Sapelo Island is characterized by strong seasonal variability. Peak Altamaha River discharge generally occurs in March and April, and discharge is reduced during summer and fall (Di Iorio and Castelao, 2013). From mid-2014 to early 2015, the Altamaha River discharge was close to the longterm average (Figure 2), with low discharge during the July and October 2014 sampling periods, and high discharge in April 2015. Consistent with that, the lowest salinity at the sampling site was observed in April 2015 (Table 1). Salinity in July 2014 was the highest, with October 2014 being characterized by intermediate values. For each season, salinity at low tide was 1-3 psu lower than during high tide (Table 1).

\section{Patterns of Dissolved Organic Carbon and CDOM Variability}

Concentrations of DOC for T0 samples were variable between different seasons and tidal conditions. During the sampling period, DOC ranged from 194 to $337 \mu \mathrm{M}$, with larger values for each season observed at low tide, which is consistent with observations from other systems (e.g., Tzortziou et al., 2008; Osterholz et al., 2018). During July and October, mean high tide DOC concentrations were not significantly different from one another ( $t$-test, $p=0.18)$. In April, when river discharge was high, mean DOC concentration was significantly different

\footnotetext{
${ }^{2}$ http://waterdata.usgs.gov

${ }^{3}$ https://gce-lter.marsci.uga.edu
}

(1.5 times higher) from both previous seasons (for both, $t$-test, $p<0.01)$. During low tide, each season's DOC concentration was significantly different from one another (ANOVA, $F=174.6$, $\mathrm{df}=2.8, p<0.01$ ), with July having the lowest DOC concentration, followed by October and then April (Table 1). Seasonal differences in DOC have been observed in previous studies of the region, where DOC concentrations tend to peak in spring as compared to summer and fall (e.g., Medeiros et al., 2017a; Letourneau and Medeiros, 2019).

Differences in DOM composition between seasons were quantified by analyzing optical properties (Table 1). At both high and low tides, the observed absorption ratio at $\lambda=250 \mathrm{~nm}$ to $\lambda=365 \mathrm{~nm}$ was smaller in April than July or October, though all months were significantly different from one another (ANOVA, high tide: $F=14.5, \mathrm{df}=2.5, p=0.02$; low tide: $F=504, \mathrm{df}=2.8$, $p<0.05)$. Decreased values for absorption ratios indicate a shift toward more aromatic structures (Peuravuori and Pihlaja, 1997), which is a typical characteristic of terrigenous DOM (Sleighter and Hatcher, 2008; Medeiros et al., 2015b). Spectral slope coefficients in April were also reduced compared to July and October, which is consistent with increased terrigenous content during spring. No differences in the mean absorption ratio were observed between samples collected at high or low tides for July and October ( $t$-test, $p>0.05$ ), while for April the difference in the ratio for high and low tide was marginally significant ( $t$-test, $p=0.047) . S_{275-295}$ were not significantly different for samples collected at high and low tide in all seasons ( $t$-test, $p>0.05$ ).

Biodegradation over a short time scale (1-day long incubation) resulted in only small and non-significant changes in DOC concentrations. Long-term dark incubations (60 days; T60) performed on high tide samples revealed larger changes, however. The percent of DOC biodegraded was slightly higher in October (11.7\%) than in April (9.0\%). The absorption ratio $\left[\mathrm{a}_{g}(250): \mathrm{a}_{g}(365)\right]$ decreased in most incubations (Table $\mathbf{1}$ ), indicating a shift toward more aromatic structures in the remaining DOM pools.

\section{Drivers of Dissolved Organic Matter Composition Variability}

DOM composition was investigated at the molecular level using FT-ICR MS analysis. Over 5,000 molecular formulae were

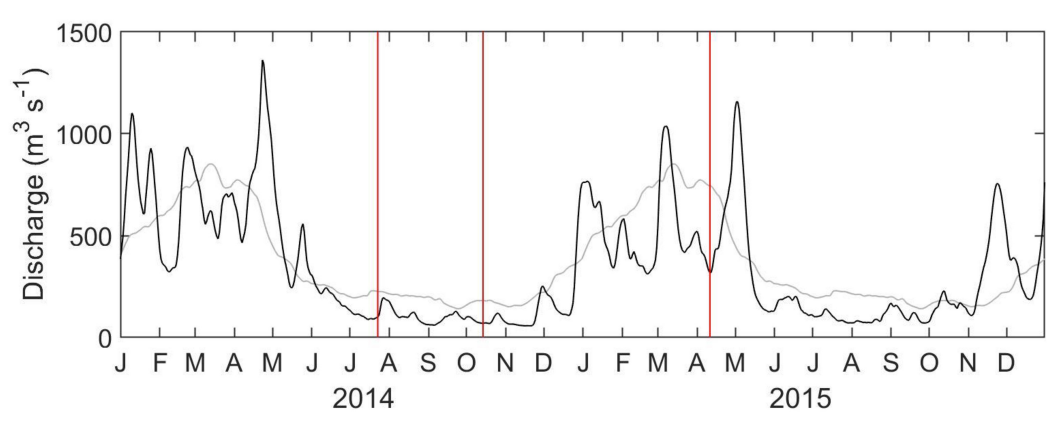

FIGURE 2 | Time series of Altamaha River discharge at Doctortown, Georgia (black). Long-term average is shown in gray. Red vertical lines indicate sampling periods. 
TABLE 1 | Environmental, bulk and optical measurements for seasonal DOM samples collected at Doboy Sound (GA) at high and low tides.

\begin{tabular}{|c|c|c|c|c|c|c|}
\hline & \multicolumn{2}{|c|}{ July 2014} & \multicolumn{2}{|c|}{ October 2014} & \multicolumn{2}{|c|}{ April 2015} \\
\hline & High tide & Low tide & High tide & Low tide & High tide & Low tide \\
\hline & \multicolumn{6}{|c|}{ Salinity } \\
\hline & 33 & 30 & 28 & 27 & 25 & 23 \\
\hline & \multicolumn{6}{|c|}{ DOC $(\mu \mathrm{M})$} \\
\hline TO & $194.0 \pm 6.7$ & $249.3 \pm 7.8$ & $198.2 \pm 5.8$ & $324.9 \pm 4.2$ & $291.1 \pm 6.3$ & $337.1 \pm 6.2$ \\
\hline T1 & $190.1 \pm 7.1$ & $250.9 \pm 8.7$ & $193.0 \pm 3.4$ & $309.4 \pm 9.4$ & $288.6 \pm 6.3$ & $331.6 \pm 4.2$ \\
\hline \multirow[t]{2}{*}{ T60 } & - & - & $175.1 \pm 3.3$ & - & $264.8 \pm 5.7$ & - \\
\hline & \multicolumn{6}{|c|}{$a_{g}(250): a_{g}(365)$} \\
\hline TO & $6.04 \pm 0.22$ & $5.97 \pm 0.10$ & $6.33 \pm 0.12$ & $6.39 \pm 0.21$ & $5.59 \pm 0.04$ & $5.68 \pm 0.03$ \\
\hline $\mathrm{T} 1$ & $6.08 \pm 0.05$ & $5.86 \pm 0.30$ & $6.19 \pm 0.06$ & $6.20 \pm 0.20$ & $5.55 \pm 0.01$ & $5.66 \pm 0.01$ \\
\hline \multirow[t]{2}{*}{ T60 } & - & - & $6.09 \pm 0.14$ & - & $5.51 \pm 0.02$ & - \\
\hline & \multicolumn{6}{|c|}{$\mathrm{S}_{275-295}\left(\times 10^{3} \mathrm{~nm}^{-1}\right)$} \\
\hline TO & $17.27 \pm 0.25$ & $16.80 \pm 0.14$ & $17.11 \pm 0.11$ & $17.38 \pm 0.19$ & $15.67 \pm 0.06$ & $15.66 \pm 0.05$ \\
\hline $\mathrm{T} 1$ & $17.30 \pm 0.10$ & $16.57 \pm 0.40$ & $17.15 \pm 0.19$ & $16.98 \pm 0.03$ & $15.60 \pm 0.13$ & $15.80 \pm 0.15$ \\
\hline T60 & - & - & $16.92 \pm 0.17$ & - & $15.83 \pm 0.06$ & - \\
\hline
\end{tabular}

assigned for triplicate samples over three seasons. The vast majority of the molecular formulae identified were observed in all seasons. Considering all replicates, there were only 36, 10 and 8 formulae that were observed exclusively in July, October and April, respectively. There were 157 formulae that were observed in October and April but not in July, however. These formulae were characterized by small $\mathrm{H} / \mathrm{C}$ and especially $\mathrm{O} / \mathrm{C}$ ratios $(\mathrm{H} / \mathrm{C}=1.02 \pm 0.31, \mathrm{O} / \mathrm{C}=0.29 \pm 0.17)$, suggesting that some of the most aromatic compounds may have been missing from samples collected during summer.

To decipher environmental drivers of DOM variability using FT-ICR MS, DOM composition for pre- and postincubation (1 day) samples collected in different seasons and tidal conditions were decomposed into principal components (Bro and Smilde, 2014). Analyses were run in Matlab using all replicates simultaneously after normalization by the standard deviation between samples and mean centering (Figure 3). Only modes that were statistically significant (95\% confidence level) are shown (Overland and Preisendorfer, 1982). Plots of PC scores are related to van Krevelen diagrams of the loadings; for a given sample, where the score of a PC is positive, DOM is relatively enriched with compounds associated with molecular formulae whose loadings for that PC are positive and relatively depleted with those whose loadings are negative.

The dominant PC (PC 1) accounted for $28 \%$ of the total variance in DOM composition in Doboy Sound during the sampling period and separated samples according to sample month. The analysis showed samples from months with lower salinities (Table 1) tending toward higher PC 1 scores (Figure 3A). Analysis of a van Krevelen diagram of the loading of PC 1 showed a tendency for high positive loadings to cluster at low $\mathrm{H} / \mathrm{C}$ ratios, and low negative loadings to cluster at high $\mathrm{H} / \mathrm{C}$ ratios (Figure 3B). This is similar to the pattern observed in riverto-ocean transects (Medeiros et al., 2015b), as the terrigenous vs. marine gradient of DOM sources in the system has previously been defined (Medeiros et al., 2015a), and terrigenous DOM is known to be enriched with molecular formulae with low H/C ratios (Sleighter and Hatcher, 2008). Thus, DOM samples were enriched with compounds with more terrigenous characteristics in April and shifted toward having a more marine character

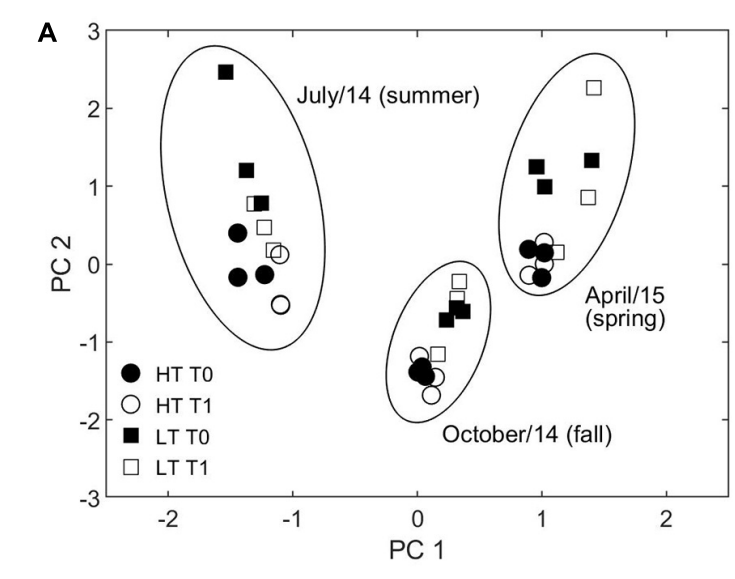

B
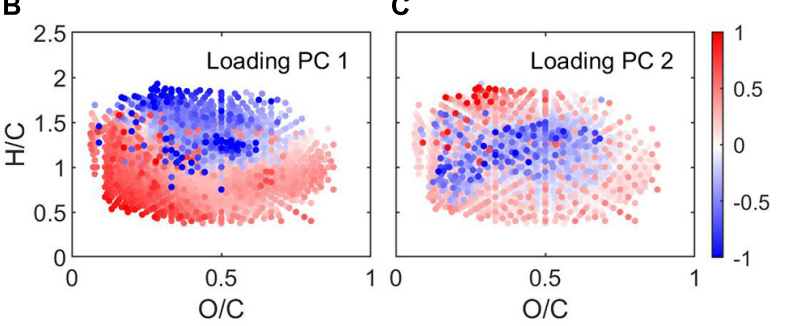

FIGURE 3 | Principal component analysis of DOM composition. (A) Scores of the principal components from the same month are circled and labeled. Solid and open symbols represent T0 and T1, respectively. Circle and square symbols represent high tide and low tide, respectively. Van Krevelen diagrams color coded with loadings of (B) PC 1 and (C) PC 2 are also shown. The first and second principal components explained $28 \%$ and $10 \%$ of the variance. 
during July. This corroborates previous studies in this region that found that DOM has a more terrigenous character during spring than summer and fall (e.g., Letourneau and Medeiros, 2019), and suggests that the most important pattern of DOM variability in the estuary occurs at seasonal scales, likely associated with variations in river discharge (Figure 2).

Within the same analysis, high and low tide samples from each season were separated along PC 2 (Figure 3A), which represented $10 \%$ of the total variance in DOM composition for the samples. This suggests the secondary mode of variance in DOM composition is influenced by tidal variability. High tide samples were relatively enriched with compounds found near the center of the van Krevelen diagram (shown in blue in Figure 3C), while low tide samples for all seasons were comparatively enriched with compounds near the periphery of the diagram (shown in red in Figure 3C). A separate plot (not shown), which contours the molecular mass of each formula as a function of its $\mathrm{O} / \mathrm{C}$ and $\mathrm{H} / \mathrm{C}$ ratios in van Krevelen space, indicates that compounds near the center of the diagram are generally characterized by higher molecular mass. Indeed, comparing the loading of PC 2 with the molecular mass of the respective compounds indicates that molecular formulae relatively enriched during low tide ( $\sim 8 \%$ of all formulae) were characterized by low molecular mass $(<\sim 300 \mathrm{Da})$, while formulae relatively enriched during high tide $(\sim 12 \%$ of all formulae) were characterized by high molecular mass ( $>\sim 400 \mathrm{Da}$ ) (Figure 4). Although low tide samples were enriched with formulae found at the lower sector of the diagram (low $\mathrm{H} / \mathrm{C}$ ratios; $3.9 \%$ of all formulae), which are characterized by high aromaticity (Koch and Dittmar, 2006, 2016), they were also enriched with formulae with high $\mathrm{H} / \mathrm{C}$ ratios (4.1\% of all formulae), which are less aromatic (Figure $3 \mathrm{C}$ ). This suggests that the overall aromaticity of the DOM may not have been strongly affected by tides. This could help explain the results described earlier based on the optical data, which showed that low and high tide samples were not significantly different with respect to the absorption ratio at $\lambda=250 \mathrm{~nm}$ to $\lambda=365 \mathrm{~nm}$

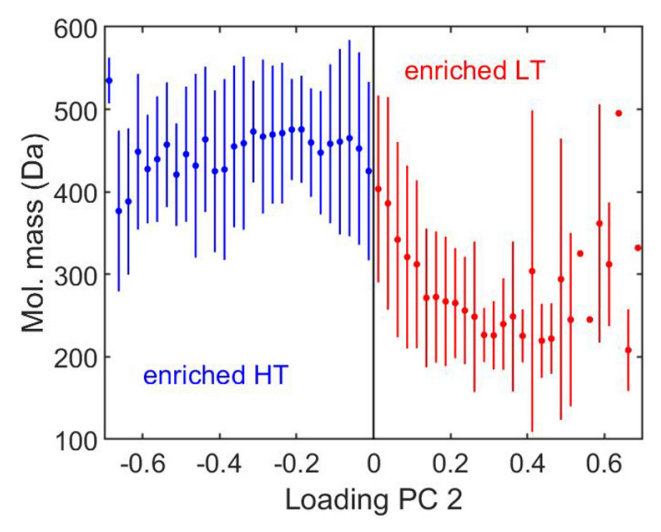

FIGURE 4 | Average \pm 1 standard deviation of molecular mass as a function of the loading of PC 2 shown in Figure $\mathbf{3 C}$. Positive loadings (shown in red) represent molecular formulae enriched in samples collected at low tide (LT), while negative loadings (shown in blue) represent formulae enriched in samples collected at high tide $(\mathrm{HT})$. and to $S_{275-295}$ (Table 1), which are related to DOM aromaticity (Peuravuori and Pihlaja, 1997) and to the terrigenous content of the DOM (Fichot and Benner, 2012), respectively.

In all cases including different seasons and tidal conditions, the impact of short-time scale biodegradation on DOM composition was comparatively small. No significant differences were observed between the PC scores for samples within a given month and tidal phase before and after the 1-day incubations (Figure 3A). Collectively, the analyses revealed that the dominant factor controlling DOM composition during the study period varied at seasonal scale. That was followed by tidal variability, with microbial degradation over short time scales having a smaller effect.

\section{Drivers of Change in Gene Expression}

Changes in DOM chemical composition are difficult to measure on short time scales because the highly labile compounds make up a small proportion of total DOM at any one time (Hansell, 2013; Moran et al., 2016). Further, methods for concentrating DOM are not efficient at capturing low molecular weight (LMW) and polar compounds, typically important components of the most labile DOM (Kujawinski, 2011). Instead, we used differences in gene expression by microbial taxa as a proxy for chemical differences in DOM composition over the 1day incubations (Vorobev et al., 2018). Homology searches of metatranscriptomic reads against marine microbial genomic data allowed expression of individual genes to be associated with their taxonomic origin.

Vorobev et al. (2018) used metatranscriptome and FT-ICR MS analyses together to characterize components of labile DOM in these samples. Here, given that gene expression data are only available for July and October 2014, we repeated the analysis of DOM composition using only samples collected in those months (Figure 5A), which yielded results consistent with those described before. Despite the fact that the chemical (FT-ICR MS) and microbiological (functional assignments of transcripts) assessments largely tracked different components of the DOM pool, we noted that the important scales over which changes occurred coincided. The largest differences in both cases were observed between seasons and then for different tidal phases, with short-term incubations having a comparatively smaller effect (Figures 5A,B). Yet, analysis of specific gene functions differentiated shifts in microbial uptake and metabolism after the 1-day incubation (Vorobev et al., 2018). Within the 50 highest transcript-recruiting reference genomes, July had statistically elevated transcript abundance of Actinobacteria $(p=0.01)$, Nitrosomondales $(p=0.04)$, Rhodospiralles $(p<0.05)$, SAR 11 $(p=0.02)$, and SAR $86(p=0.03)$ as compared to October, while in October the Archaea taxon Euryarchaeota $(p<0.05)$ was the greatest contributor to metatranscriptomes (Figure 6). Following the pattern of DOM driver importance, tides secondarily impacted taxon-based gene expression patterns. Specifically, we observed small variations in the taxa contributing most to gene expression for different tidal stages within a season. While no differences in transcript production by taxon was observed between tides during October, in July the Verrucomicrobia population for T0 samples increased during low tides $(p<0.05)$ 

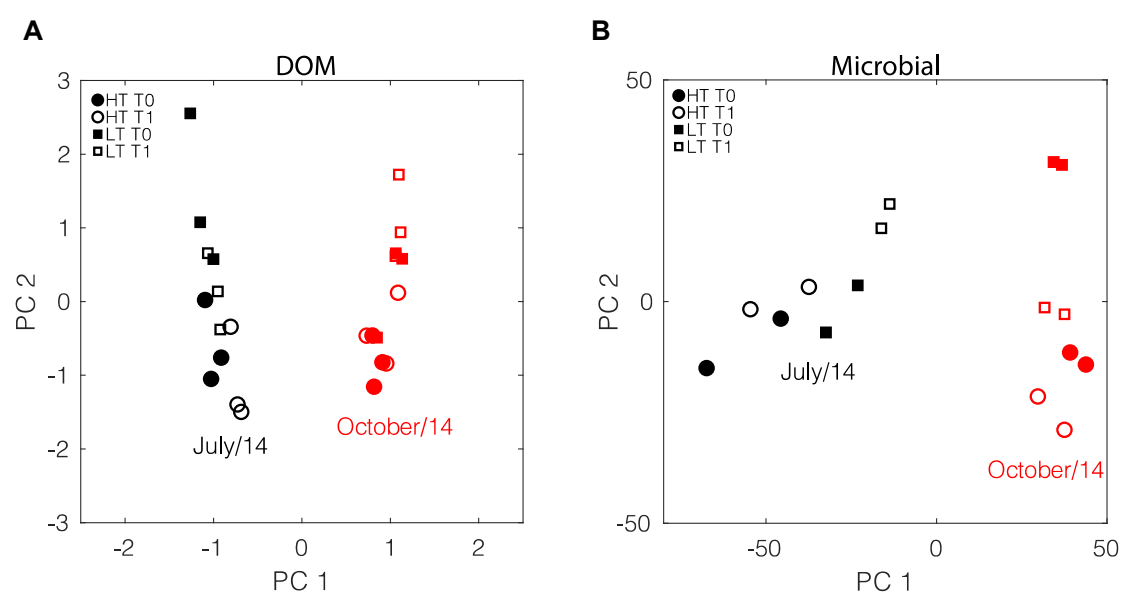

FIGURE 5 | Comparison of patterns of variability between chemical and microbial data. Black and red symbols represent July and October, respectively. Solid and open symbols represent T0 and T1, respectively. Circle and square symbols represent high tide and low tide, respectively. (A) PCA scores of DOM composition. The first and second principal components explained $32 \%$ and $9 \%$ of the variance. (B) Corresponding PCA scores for gene expression data. The first and second principal components explained $66 \%$ and $13 \%$ of the variance.

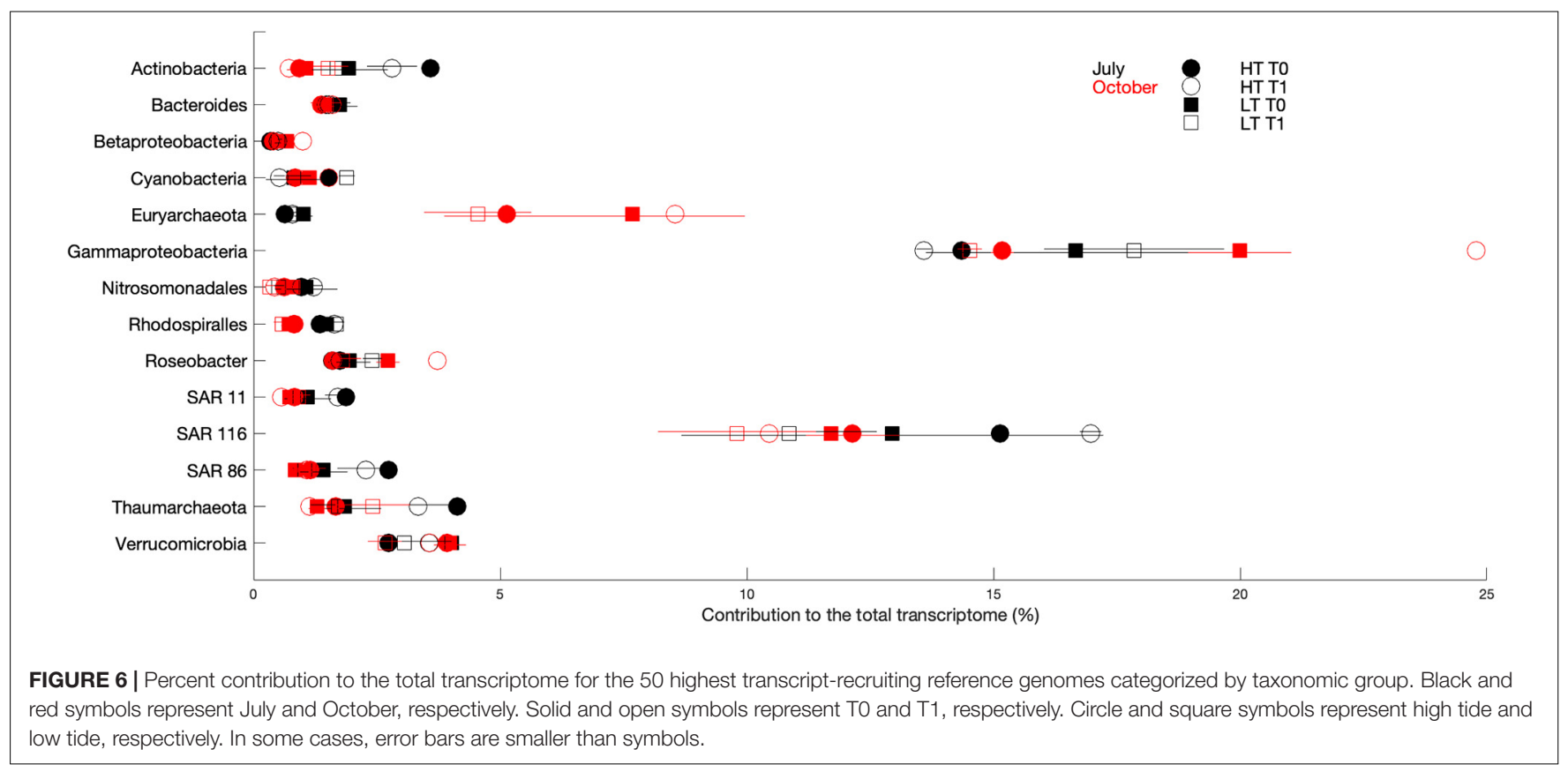

(Figure 6). Kara and Shade (2009) reported that over a time scale of a few days (74 h), the microbial community composition near Doboy Sound was most impacted by tides, which is consistent with our observations that once seasonality is removed, the influence of tides becomes more evident.

\section{Dissolved Organic Matter Compositional Variability on Long Timescales}

In the absence of highly labile compounds, microbial transformation is constrained to the components of DOM that are more recalcitrant and less energetically favorable to metabolize. Over time, these slower microbial transformations of DOM accumulate and can typically be observed after several weeks (e.g., Medeiros et al., 2017b; Logozzo et al., 2021). To observe effects of long-term biodegradation on DOM and quantify the relative importance in comparison to other processes, analyses were repeated including the samples collected at the end of the 60-day long incubations (T60). Given the constraints imposed by the PC analyses, however, it is difficult to interpret transformations associated with tidal variability and long-term biodegradation considering all samples together, since additional modes of variability must be orthogonal to the dominant mode associated with seasonal variability. This often results in variability associated with processes of secondary importance being split into more than one mode 


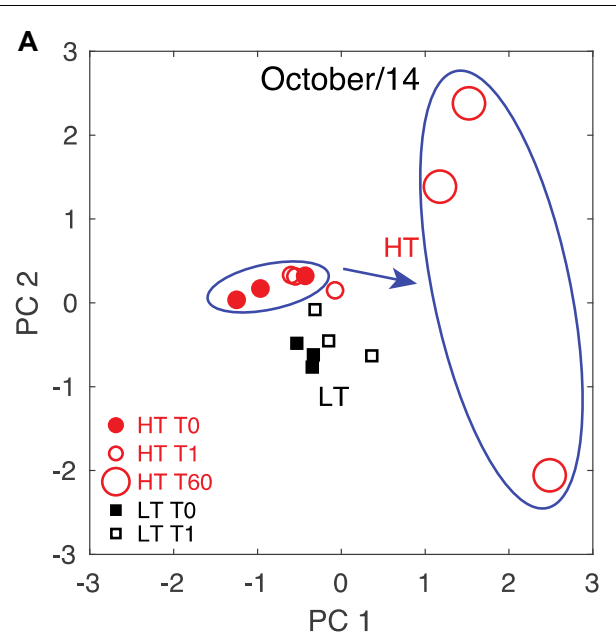

B

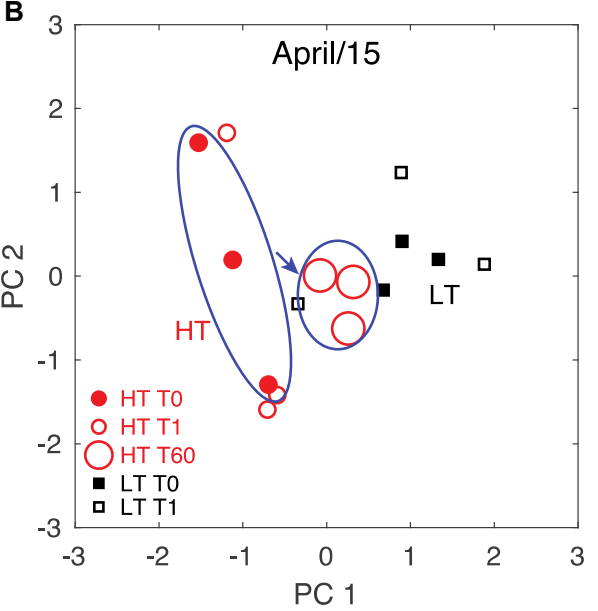

FIGURE 7 | Principal component analyses of DOM composition including long-term incubations for (A) October 2014 and (B) April 2015. T0 and T60 samples are grouped with ellipses for emphasis, while arrows emphasize the extent of DOM transformation over the incubation period based on the first two principal components. The first and second principal components explained $26 \%$ and $21 \%$ of the variance in (A) and $24 \%$ and $13 \%$ in (B).

(Medeiros et al., 2017b). Thus, we chose to remove the influence of seasonal variability by repeating the analysis separately for each season. This allowed us to assess the relative contributions of tidal variability versus long-term biodegradation to changes in DOM composition in each season.

During October 2014, the dominant PC separated the high tide T60 samples from both T0 and T1 collected during high or low tide, indicating that the change in DOM composition due to the long-term degradation was larger than the differences in DOM composition observed between different tidal phases (Figure 7A). Conversely, during April 2015 the high tide T0-T60 samples represented a smaller difference in DOM composition compared to the difference found between high tide and low tide T0 samples (Figure 7B). Thus, the change in DOM composition due to long-term incubations was larger than due to tidal variability in October, but the opposite was true in April. We note that the salinity difference between high and low tide conditions at an oceanographic mooring located $\sim 3 \mathrm{~km}$ from our sampling location was significantly higher in April 2015 than in October 2014, and the average salinity was lower in spring (Figure 8). This is consistent with river discharge data and indicates that more freshwater was present in the system in April (Table 1).

\section{DISCUSSION}

DOM composition and transformation play an important role in a variety of processes in estuaries, including nutrient availability, bacterial production, and carbon export to the coastal ocean (Hedges et al., 1997; Aitkenhead-Peterson et al., 2003; Crump et al., 2009; Moran et al., 2016; Medeiros et al., 2017a). Several processes are known to influence DOM composition in estuarine settings at various spatial and temporal scales. Here, we assess the relative importance of seasonality, tides and microbial processing on variations in DOM composition in the estuary around Sapelo Island, off the Southeastern U.S. Our analyses revealed that the primary mode of variability in DOM composition in Doboy Sound occurs at the seasonal scale and is associated with the terrigenous content of the DOM. This is consistent with previous studies that have shown that the seasonal delivery of freshwater to the system plays an important role controlling DOM composition in the estuary (Medeiros et al., 2015a). Given that our samples were collected during 3 instances in the year, we cannot compute correlations between DOM composition and environmental drivers such as river discharge. However, Letourneau and Medeiros (2019) analyzed monthly time series of DOM composition at the mouth of the Altamaha River to show that the terrigenous signature of the DOM delivered to the estuary is highly correlated with river discharge when river flow is higher than $150 \mathrm{~m}^{3} \mathrm{~s}^{-1}$, while for low discharge conditions the signature of marsh-derived inputs can be observed. Letourneau and Medeiros (2019) samples were all collected in high tide conditions, however, so they were not able to assess the relative importance of seasonal variability associated with riverine inputs and variability at semi-diurnal scales associated with tides, which has been shown to be of critical importance in other estuaries (e.g., Tzortziou et al., 2008; Cao and Tzortziou, 2021). By analyzing samples from different seasons collected twice on each tidal cycle, we were able to expand on Letourneau and Medeiros (2019) analyses by directly comparing the relative importance of riverine inputs and tidal stage.

Although seasonal variability likely due to riverine inputs is dominant, the analyses also revealed significant increases in DOC during low tide conditions, which is consistent with results of Tzortziou et al. (2008) for Chesapeake Bay. Optical analyses (absorption ratio at $\lambda=250 \mathrm{~nm}$ to $\lambda=365 \mathrm{~nm}$; spectral slope: $S_{275-295}$ ) revealed no significant differences in DOM composition between high and low tide conditions, however. This is surprising, considering that Tzortziou et al. (2008) reported strong tidal modulation in optical properties in Chesapeake Bay, with a clear signature of marsh-exported CDOM during low tide. Given that our samples were collected in a relatively wide $(\sim 220 \mathrm{~m})$ channel close to the main channel of Doboy Sound (which is itself $1.6 \mathrm{~km}$ wide and $10 \mathrm{~m}$ deep), 

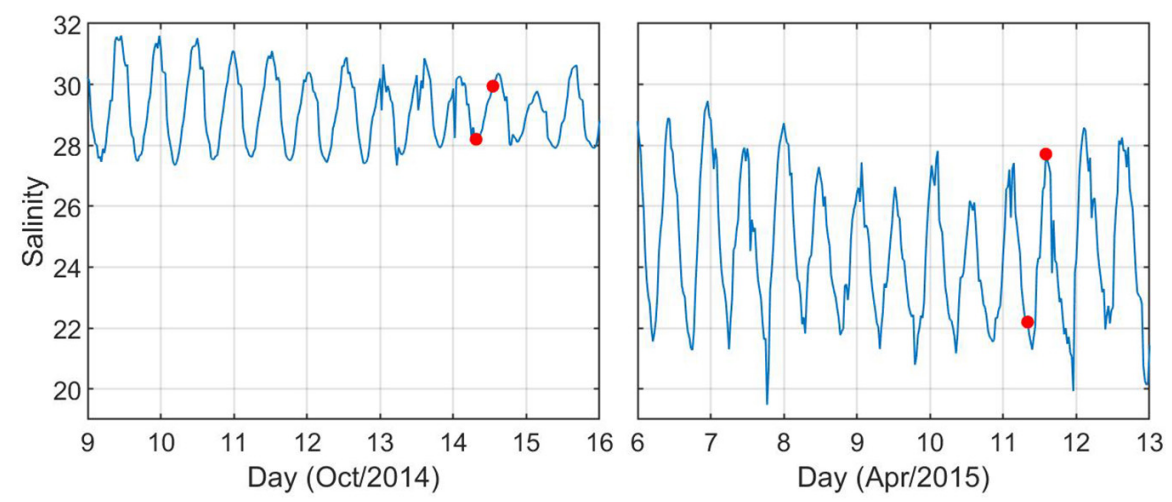

FIGURE 8 | Time series of salinity at oceanographic mooring GCE6 at the main channel of Doboy Sound (see Figure 1 for location) during October 2014 and April 2015 collections. Red circles indicate timing of sample collection.

relatively far from narrow and shallow tidal creeks (see Figure $\mathbf{1}$ for sampling location), it is possible that the influence of marshderived DOM introduced at low tide was diluted at our study site, resulting in a smaller difference in DOM composition between high and low tide conditions. The chemical analyses at the molecular level revealed that DOM at high and low tide conditions have distinct compositions, though. During low tide, DOM in all seasons was relatively enriched with highly aromatic compounds (Koch and Dittmar, 2006, 2016), which is consistent with the observations from Chesapeake Bay (Tzortziou et al., 2008). However, DOM during low tide was also relatively enriched with aliphatic compounds characterized by high $\mathrm{H} / \mathrm{C}$ ratios (Seidel et al., 2014). Thus, the overall aromaticity of the added DOM may not be much different than the original signature, which could contribute to the optical signatures reflecting the average aromaticity of the DOM (Peuravuori and Pihlaja, 1997) not being significantly different between low and high tide. We were not able to quantify the specific contribution of the input of the aromatic or aliphatic compounds to the optical signature of each sample since that would depend on the change in concentration and in the extinction coefficient of each compound, none of which are known.

We were also able to identify the relative contribution of microbial degradation to DOM compositional changes, which showed that on short time scales transformations due to microbial activity were small when compared to variations associated with seasonal or tidal variability. This is likely affected by the low inventory of biologically labile compounds maintained in seawater combined with the poor capture efficiency of LMW molecules by solid-phase extraction methods (Kujawinski, 2011; Moran et al., 2016). Short-term incubations were done with whole seawater to mimic in situ conditions as close as possible, and thus included a full range of trophic levels including bacterial grazers. The bacterial cell number decreased by 20\% during the incubation; however, numbers were between 1.3 and 2.4 million cells per milliliter, and therefore were sufficient in number to assimilate available DOM.

Collectively, this analysis provided an assessment of the relative importance of these three processes in modifying DOM composition during the study period. The metatranscriptomics data largely mirrored these results, with tidal scale being of secondary importance relative to seasonal scale. As was the case for DOM composition, short-term incubations were found to have a smaller effect on variability in the microbial data. It is likely that both DOM chemical composition and the microbial response to DOM composition primarily followed terrestrial versus marine water mass budgets in the estuary (e.g., higher influence of freshwater in April during peak river discharge; high influence of oceanic water during high tide for each season) as has been observed in the Delaware Estuary (Osterholz et al., 2018).

Although short-term biodegradation was found to have a comparatively small effect on DOM composition, our analyses indicate that over longer time scales microbial activity significantly altered the DOM chemistry. Indeed, while DOM composition changes in the 1-day incubations reported here have been previously shown to be consistent with microbial cleavage of functional groups from semi-polar compounds (Vorobev et al., 2018), changes over longer time scales are consistent with progressive transformation of functional groups of intermediates in degradation pathways, resulting in larger net changes in DOM composition (Medeiros et al., 2017b). Our analyses indicate that over these longer scales, microbial biodegradation can produce DOM composition differences comparable to that observed in response to tides, previously recognized to be important (e.g., Tzortziou et al., 2008; Cao et al., 2018; Cao and Tzortziou, 2021). Thus, if estuarine residence time is large in comparison to the time scale of biodegradation, microbial activity can exert a firstorder effect on DOM composition. Here, estuarine water was incubated for 60 days, which is longer than the residence time in the system (Wang et al., 2017). However, Medeiros et al. (2017b) pursued dark incubations of Doboy Sound water for different durations and identified molecular formulae whose relative abundances were enriched or depleted during the incubations. They showed that the difference in the average mass of these formulae was similar for incubations lasting 35 and 70 days. This suggests that significant changes in DOM composition occur on times scales of 1 month. Logozzo et al. (2021) used dark incubations of Chesapeake Bay water to show that significant 
changes in DOC concentration and DOM composition due to microbial activity can occur on time scales of 2 weeks. Microbial activity can therefore play an important role controlling DOM dynamics in at least some areas of the estuary. Residence time at the Altamaha River averages only a few days (Sheldon and Alber, 2002) but can reach several weeks in many parts of the estuary (Wang et al., 2017). For example, DOM composition was significantly enriched in terrigenous molecules 30 days after the passage of Hurricane Irma in 2017, indicating a residence time of at least 1 month for organic material introduced during the passage of the storm (Letourneau et al., 2021) and sufficient time for microbial transformation before export to the coastal ocean.

The relative importance of tidal variability versus long-term incubation differed between October 2014 and April 2015. While tidal variability drove larger DOM changes than did long-term biodegradation in spring, the opposite was true in the fall. This may be related to seasonal differences in DOM lability, which has often been linked to DOM source (Obernosterer and Benner, 2004), including for this system (e.g., Medeiros et al., 2017b). More labile components of the DOM may have been available to microbes in October 2014 than in April 2015, resulting in larger DOM transformation. Indeed, we observed slightly more DOC long-term degradation in October (11.7\%) than in April (9.0\%) (Table 1). Alternatively, the high and low tide difference in DOM composition in April 2015 could be related to a greater freshwater content in the estuary during that time. Time series data of salinity at the main channel of Doboy Sound (see Figure 1 for location), $3 \mathrm{~km}$ from our sampling site, indicated that the salinity difference between high and low tide conditions in October 2014 was about 2 psu, but in April 2015 that difference was about $6 \mathrm{psu}$ (Figure 8). Thus, it is possible that the comparatively larger importance of tidal variability in April 2015 was simply because a stronger gradient in freshwater content (and presumably in DOM composition) was advected back and forth by tidal currents across our sampling location. This also highlights an important aspect of the influence of tides on DOM composition in estuaries. Although in some cases variability may be associated with an input of organic matter, such as from salt marshes (Tzortziou et al., 2008), representing an actual alteration of DOM composition, other tidally-linked changes in DOM composition at a given site may be due to a gradient of DOM advected back and forth across the site.

We note that our analyses cannot fully resolve seasonal variability, given that samples were collected in three different months in a single 12-month period. As such, variability at different scales (e.g., interannual) may have been aliased into the seasonal component of variability extracted by our analyses. Our results for different months are consistent with those reported by Letourneau and Medeiros (2019), however, suggesting that a similar pattern of variability is observed in different years. Similarly, because of sampling constraints, only 2 samples (with triplicates) were collected to represent tidal differences in each season, one at high and another at low tide. Although this does not allow for tidal variability to be fully resolved or for correlations with sea level height to be computed, the fact that results were quantitatively similar for all seasons (i.e., shift in second principal component for low tide samples was similar for all months; Figure 3) suggests that the change in composition reported here is robust and repeatable for different tidal cycles. Our analyses indicate that short-term transformations due to biodegradation are small compared to other drivers for the fraction of the DOM captured by our analysis, which excludes LMW compounds known to be highly labile (Kujawinski, 2011) as well as classes of compounds often targeted by microorganisms (e.g., polysaccharides, Rich et al., 1996). Thus, the true importance of biodegradation changing DOM composition in estuaries over short-time scales may be underestimated by our analyses. Lastly, we focused on only a few factors that could be affecting DOM composition in estuaries, representing a first step toward assessing their relative importance. Future studies attempting to isolate and quantify the relative importance of other drivers, such as photochemistry, flocculation, and inputs associated with phytoplankton and zooplankton activity (Hedges, 1992), will advance our understanding of DOM dynamics in complex coastal environments.

Assessing the contribution of different drivers to DOM composition in estuaries is critically important to understand future changes in these systems. The atmospheric supply of water vapor to the Southeastern U.S. is predicted to be modestly reduced in the future (Seager et al., 2009), and the frequency of low Altamaha River discharge conditions has shown signs of increasing in recent decades (e.g., Medeiros et al., 2015a). Given that change in DOM composition at seasonal scales, likely associated with river discharge, is the most important mode of variability in the system, predicted changes in the hydroclimate can be accompanied by changes in DOM composition. Future changes in river discharge (and other factors driving local circulation, such as wind forcing) will likely also affect estuarine residence time (Sheldon and Alber, 2002; Wang et al., 2017) and therefore the time available for microbial activity to modify the DOM before export to the coastal ocean. Lastly, understanding the relative contributions of the various processes investigated here is important to highlight the likely factors explaining spatial and/or temporal differences in DOM composition in estuarine regions, and to set the context for observed differences in DOM composition between different systems.

\section{DATA AVAILABILITY STATEMENT}

The datasets presented in this study can be found in online repositories. The names of the repository/repositories and accession number(s) can be found below: https://www.bco-dmo. org/project/472758, BCO-DMO 472758.

\section{AUTHOR CONTRIBUTIONS}

PM and MM conceived and designed the study. RM and PM conducted the FT-ICR MS analyses. AV and MM conducted the metatranscriptomic analyses. RM wrote the first draft of the manuscript with significant inputs from PM. All authors discussed the results and commented on the manuscript. 


\section{FUNDING}

This research was supported by the National Science Foundation through grants OCE 1902131, 1948104, and 1356010, and through the GCE-LTER program (OCE 1832178).

\section{ACKNOWLEDGMENTS}

We thank the two reviewers and the editor for their constructive comments and suggestions, which led to an improved

\section{REFERENCES}

Aitkenhead-Peterson, J. A., McDowell, W. H., and Neff, J. C. (2003). "Sources, production, and regulation of allochthonous dissolved organic matter inputs to surface waters," in Aquatic Ecosystems, eds S. E. G. Findlay and R. L. Sinsabaugh (Cambridge, MA: Elsevier), 25-70.

Amon, R. M. W., and Benner, R. (1996). Bacterial utilization of different size classes of dissolved organic matter. Limnol. Oceanogr. 41, 41-51. doi: 10.4319/lo.1996. 41.1.0041

Bauer, J., Cai, W. J., Raymond, P., Bianchi, T. S., Hopkinson, C. S., and Regnier, P. A. G. (2013). The changing carbon cycle of the coastal ocean. Nature 504, 61-70. doi: 10.1038/nature12857

Bianchi, T. S. (2006). "Organic matter cycling" in Biogeochemistry of Estuaries (New York, NY: Oxford University Press), 177-221. Available online at: https://oxford.universitypressscholarship.com/view/10.1093/oso/ 9780195160826.001.0001/isbn-9780195160826

Bro, R., and Smilde, A. (2014). Principal component analysis. Anal. Methods 6, 2812-2831.

Canuel, E. A., and Hardison, A. K. (2016). Sources, ages, and alteration of organic matter in estuaries. Ann. Rev. Mar. Sci. 8, 409-434. doi: 10.1146/annurevmarine-122414-034058

Cao, F., and Tzortziou, M. (2021). Capturing dissolved organic carbon dynamics with Landsat- 8 and Sentinel-2 in tidally influenced wetland-estuarine systems. Sci. Total Environ. 777:145910. doi: 10.1016/j.scitotenv.2021.145910

Cao, F., Tzortziou, M., Hu, C., Mannino, A., Fichot, C. G., Del Vecchio, R., et al. (2018). Remote sensing retrievals of colored dissolved organic matter and dissolved organic carbon dynamics in North American estuaries and their margins. Remote Sens. Environ. 205, 151-165. doi: 10.1016/j.rse.2017.1 1.014

Corilo, Y. E. (2014). PetroOrg Software. Tallahassee, FL: Florida State University.

Crump, B. C., Peterson, B. J., Raymond, P. A., Amon, R. M. W., Rinehart A., McClelland, J. W., et al. (2009). Circumpolar synchrony in big river bacterioplankton. Proc. Natl. Acad. Sci. U.S.A. 106, 21208-21212. doi: 10.1073/ pnas.0906149106

Di Iorio, D., and Castelao, R. M. (2013). The dynamical response of salinity to freshwater discharge and wind forcing in adjacent estuaries on the Georgia coast. Oceanography 26, 44-51. doi: 10.5670/oceanog.2013.44

D’Sa, E. J., Steward, R. G., Vodacek, A., Blough, N. V., and Phinney, D. (1999). Determining optical absorption of colored dissolved organic matter in seawater with a liquid capillary waveguide. Limnol. Oceanogr. 44, 1142-1148.

Fichot, C. G., and Benner, R. (2012). The spectral slope coefficient of chromophoric dissolved organic matter (S275-295) as a tracer of terrigenous dissolved organic carbon in river-influenced ocean margins. Limnol. Oceanogr. 57, 1453-1466. doi: $10.4319 /$ lo.2012.57.5.1453

Gifford, S. M., Sharma, S., Booth, M., and Moran, M. A. (2013). Expression patterns reveal niche diversification in a marine microbial assemblage. ISME J. 7, 281-298.

Gifford, S. M., Sharma, S., Rinta-Kanto, J. M., and Moran, M. A. (2011). Quantitative analysis of a deeply sequenced marine microbial metatranscriptome. ISME J. 5, 461-472.

Hansell, D. A. (2005). Dissolved organic carbon reference material program. Eos 86, 318-318. doi: 10.1029/2005EO350003 manuscript. We also thank A. McKenna and H. Chen for their assistance, and Y. Corilo with PetroOrg software use (https://nationalmaglab.org/user-facilities/icr/icr-software). We acknowledge the help of Roger Nilsen at the Georgia Genomics and Bioinformatics Core and the University of Georgia’s Georgia Advanced Computing Resource Center. A portion of this work was performed at the National High Magnetic Field Laboratory ICR User Facility, which is supported by the National Science Foundation Division of Chemistry and Division of Materials Research through DMR-1644779 and the State of Florida. This is UGAMI contribution number 2001.

Hansell, D. A. (2013). Recalcitrant dissolved organic carbon fractions. Annu. Rev. Mar. Sci. 5, 421-445.

Hansell, D. A., Carlson, C. A., Repeta, D. J., and Schlitzer, R. (2009). Dissolved organic matter in the ocean: a controversy stimulates new insights. Oceanography 22, 202-211. doi: 10.5670/oceanog.2009.109

Hedges, J. I. (1992). Global biogeochemical cycles: progress and problems. Mar. Chem. 39, 67-93.

Hedges, J. I., Keil, R. G., and Benner, R. (1997). What happens to terrestrial organic matter in the ocean? Org. Geochem. 27, 195-212.

Helms, J. R., Stubbins, A., Ritchie, J. D., Minor, E. C., Kieber, D. J., and Mopper, K. (2008). Absorption spectral slopes and slope ratios as indicators of molecular weight, source, and photobleaching of chromophoric dissolved organic matter. Limnol. Oceanogr. 53, 955-969.

Hernes, P. J., and Benner, R. (2003). Photochemical and microbial degradation of dissolved lignin phenols: implications for the fate of terrigenous dissolved organic matter in marine environments. J. Geophys. Res. Oceans. 108:C9. doi: $10.1029 / 2002$ jc001421

Hollibaugh, J., Gifford, S., Moran, M. A., Ross, M. J., Sharma, S., and Tolar, B. B. (2013). Seasonal variation in the metratranscriptomes of a Thaumarchaeota population from SE USA coastal waters. ISME J. 8, 685-698. doi: 10.1038/ismej. 2013.171

Hollibaugh, J., Gifford, S., Sharma, S., Bano, N., and Moran, M. A. (2011). Metatranscriptomic analysis of ammonia-oxidizing organisms in an estuarine bacterioplankton assemblage. ISME J. 5, 866-878. doi: 10.1038/ismej.2010.172

Kara, E., and Shade, A. (2009). Temporal dynamics of south end tidal creek (Sapelo Island, Georgia) bacterial communities. Appl. Environ. Microbiol. 75, 1058-1064.

Kieber, R. J., Zhou, X., and Mopper, K. (1990). Formation of carbonyl compounds from UV-induced photodegradation of humic substances in natural waters: fate of riverine carbon in the sea. Limnol. Oceanogr. 35:1503.

Kim, S., Kramer, R. W., and Hatcher, P. G. (2003). Graphical method for analysis of ultrahigh-resolution broadband mass spectra of natural organic matter, the van Krevelen diagram. Anal. Chem. 75, 5336-5344. doi: 10.1021/ac034415p

Koch, B. P., and Dittmar, T. (2006). From mass to structure: an aromaticity index for high-resolution mass data of natural organic matter. Rapid Commun. Mass Spectrom. 20, 926-932. doi: 10.1002/rcm.2386

Koch, B. P., and Dittmar, T. (2016). From mass to structure: an aromaticity index for high-resolution mass data of natural organic matter. Rapid Commun. Mass Spectrom. 30:250. doi: 10.1002/rcm.7433

Kujawinski, E. B. (2011). The impact of microbial metabolism on marine dissolved organic matter. Ann. Rev. Mar. Sci. 3, 567-599. doi: 10.1146/annurev-marine120308-081003

Letourneau, M. L., and Medeiros, P. M. (2019). Dissolved organic matter composition in a marsh-dominated estuary: response to seasonal forcing and to the passage of a hurricane. J. Geophys. Res. Biogeosci. 124, 1545-1559. doi: 10.1029/2018jg004982

Letourneau, M. L., Schaefer, S. C., Chen, H., McKenna, A. M., Alber, M., and Medeiros, P. M. (2021). Spatio-temporal changes in dissolved organic matter composition along the salinity gradient of a marsh-influenced estuarine complex. Limnol. Oceanogr. 66, 3040-3054. doi: 10.1002/lno.11857

Logozzo, L., Tzortziou, M., Neale, P., and Clark, J. B. (2021). Photochemical and microbial degradation of chromophoric dissolved organic matter exported from 
tidal marshes. J. Geophys. Res. Biogeosci. 126:e2020JG005744. doi: 10.1029/ 2020JG005744

Love, M. I., Huber, W., and Anders, S. (2014). Moderated estimation of fold change and dispersion for RNA-seq data with DESeq2. Genome Biol. 15:550. doi: 10.1186/s13059-014-0550-8

Medeiros, P. M., Seidel, M., Gifford, S. M., Ballantyne, F., Dittmar, T., Whitman, W. B., et al. (2017b). Microbially-mediated transformations of estuarine dissolved organic matter. Front. Mar. Sci. 4:69. doi: 10.3389/fmars.2017.00069

Medeiros, P. M., Babcock-Adams, L., Seidel, M., Castelao, R. M., Di Iorio, D., Hollibaugh, J. T., et al. (2017a). Export of terrigenous dissolved organic matter in a broad continental shelf. Limnol. Oceanogr. 62, 1718-1731. doi: 10.1002/lno. 10528

Medeiros, P. M., Seidel, M., Dittmar, T., Whitman, W. B., and Moran, M. A. (2015a). Drought-induced variability in dissolved organic matter composition in a marsh-dominated estuary. Geophys. Res. Lett. 42, 6446-6453. doi: 10.1002/ 2015GL064653

Medeiros, P. M., Seidel, M., Ward, N. D., Carpenter, E. J., Gomes, H. R., Niggemann, J., et al. (2015b). Fate of the Amazon River dissolved organic matter in the tropical Atlantic Ocean. Global Biogeochem. Cycles 29, 677-690. doi: 10.1002/2015gb005115

Meyer, J. L., Edwards, R. T., and Risley, R. (1987). Bacterial growth on dissolved organic carbon from a blackwater river. Microb. Ecol. 13, 13-29. doi: 10.1007/ BF02014960

Miller, W. L., and Moran, M. A. (1997). Interaction of photochemical and microbial processes in the degradation of refractory dissolved organic matter from a coastal marine environment. Limnol. Oceanogr. 42, 1317-1324. doi: 10.4319/ lo.1997.42.6.1317

Moran, M. A., and Hodson, R. E. (1989). Formation and bacterial utilization of dissolved organic carbon derived from detrital lignocellulose. Limnol. Oceanogr. 34, 1034-1047. doi: 10.4319/lo.1989.34.6.1034

Moran, M. A., and Hodson, R. E. (1994). Dissolved humic substances of vascular plant origin in a coastal marine environment. Limnol. Oceanogr. 39, 762-771.

Moran, M. A., Kujawinski, E. B., Stubbins, A., Fatland, R., Aluwihare, L. I., Buchan, A., et al. (2016). Deciphering ocean carbon in a changing world. Proc. Natl. Acad. Sci. U.S.A. 113, 3143-3151. doi: 10.1073/pnas.1514645113

Moran, M. A., Sheldon, W. M., and Sheldon, J. E. (1999). Biodegradation of riverine dissolved organic carbon in five estuaries of the southeastern United States. Estuaries 22, 55-64.

Noriega, C., and Araujo, M. (2014). Carbon dioxide emissions from estuaries of northern and northeastern Brazil. Sci. Rep. 4:6164. doi: 10.1038/srep06164

Obernosterer, I., and Benner, R. (2004). Competition between biological and photochemical processes in the mineralization of dissolved organic carbon. Limnol. Oceanogr. 49, 117-124.

Osburn, C. L., Atar, J. N., Boyd, T. J., and Montgomery, M. T. (2019). Antecedent precipitation influences the bacterial processing of terrestrial dissolved organic matter in a North Carolina estuary. Estuar. Coast. Shelf Sci. 221, 119-131. doi: 10.1016/j.ecss.2019.03.016

Osterholz, H., Kirchman, D. L., Niggemann, J., and Dittmar, T. (2018). Diversity of bacterial communities and dissolved organic matter in a temperate estuary. FEMS Microbiol. Ecol. 94:8. doi: 10.1093/femsec/fiy119

Osterholz, H., Singer, G., Wemheuer, B., Daniel, R., Simon, M., Niggemann, J., et al. (2016). Deciphering associations between dissolved organic molecules and bacterial communities in a pelagic marine system. ISME J. 10, 1717-1730. doi: 10.1038/ismej.2015.231

Overland, J. E., and Preisendorfer, R. W. (1982). A significance test for principal components applied to a cyclone climatology. Mon. Weather Rev. 110, 1-4.

Peuravuori, J., and Pihlaja, K. (1997). Molecular size distribution and spectroscopic properties of aquatic humic substances. Anal. Chim. Acta 337, 133-149. doi: 10.1016/s0003-2670(96)00412-6

Poretsky, R. S., Bano, N., Buchan, A., LeCleir, G., Kleikemper, J., Pickering, M., et al. (2005). Analysis of microbial gene transcripts in environmental samples. Appl. Environ. Microbiol. 71:7. doi: 10.1128/AEM.71.7.4121-4126.2005

Poretsky, R. S., Sun, S., Mou, X., and Moran, M. A. (2010). Transporter genes expressed by coastal bacterioplankton in response to dissolved organic carbon. Environ. Microbiol. 12, 616-627. doi: 10.1111/j.1462-2920.2009.02102.x

Rich, J., Ducklow, H., and Kirchman, D. L. (1996). Concentrations and uptake of neutral monosaccharides along $14^{\circ} \mathrm{W}$ in the equatorial Pacific: contribution of glucose to heterotrophic bacterial activity and the DOM flux. Limnol. Oceanogr. $41,595-604$.
Savory, J. J., Kaiser, N. K., McKenna, A. M., Xian, F., Blakney, G. T., Rodgers, R. P., et al. (2011). Parts-per-billion Fourier transform ion cyclotron resonance mass measurement accuracy with a "walking" calibration equation. Anal. Chem. 83, 1732-1736. doi: 10.1021/ac102943z

Schaefer, S. C., and Alber, M. (2007). Temperature controls a latitudinal gradient in the proportion of watershed nitrogen exported to coastal ecosystems. Biogeochemistry 85, 333-346.

Seager, R., Tzanova, A., and Nakamura, J. (2009). Drought in the southeastern United States: causes, variability over the last millennium, and the potential for future hydroclimate change. J. Clim. 22, 5021-5045. doi: 10.1175/2009jcli2 683.1

Seidel, M., Beck, M., Riedel, T., Waska, H., Suryaputra, I. G. N. A., Schnetger, B., et al. (2014). Biogeochemistry of dissolved organic matter in an anoxic intertidal creek bank. Geochim. Cosmochim. Acta 140, 418-434. doi: 10.1016/j.gca.2014. 05.038

Sheldon, J. E., and Alber, M. (2002). A comparison of residence time calculations using simple compartment models of the Altamaha River estuary, Georgia. Estuaries Coast. 25, 1304-1317. doi: 10.1007/bf0269 2226

Sholkovitz, E. R. (1976). Flocculation of dissolved organic and inorganic matter during the mixing of river water and seawater. Geochim. Cosmochim. Acta 4, 831-845.

Sleighter, R. L., and Hatcher, P. G. (2008). Molecular characterization of dissolved organic matter (DOM) along a river to ocean transect of the lower Chesapeake Bay by ultrahigh resolution electrospray ionization Fourier transform ion cyclotron resonance mass spectrometry. Mar. Chem. 110, 140-152. doi: 10. 1016/j.marchem.2008.04.008

Tzortziou, M., Neale, P. J., Osburn, C. L., Megonigal, J. P., Maie, N., and Jaffe, R. (2008). Tidal marshes as a source of optically and chemically distinctive colored dissolved organic matter in the Chesapeake Bay. Limnol. Oceanogr. 53, 148-159.

Vorobev, A., Sharma, S., Yu, M. Y., Lee, J., Washington, B. J., Whitman, W. B., et al. (2018). Identifying labile DOM components in a coastal ocean through depleted bacterial transcripts and chemical signals. Environ. Microbiol. 20, 3012-3030. doi: $10.1111 / 1462-2920.14344$

Walther, J. V. (2013). "Understanding the earth's natural resources: an introduction," in Earth's Natural Resources (Burlington, MA: Jones and Bartlett Learning), 1-26.

Wang, Y., Castelao, R. M., and Di Iorio, D. (2017). Salinity variability and water exchange in interconnected estuaries. Estuaries Coast. 40, 917-929. doi: 10. 1007/s12237-016-0195-9

Watanabe, K., and Kuwae, T. (2015). How organic carbon derived from multiple sources contributes to carbon sequestration processes in a shallow coastal system? Glob. Chang. Biol. 21, 2612-2623. doi: 10.1111/g cb. 12924

Wu, Z., Rodgers, R. P., and Marshall, A. G. (2004). Two- and three-dimensional van Krevelen diagrams: a graphical analysis complementary to the Kendrick mass plot for sorting elemental compositions of complex organic mixtures based on ultrahigh-resolution broadband Fourier transform ion cyclotron resonance mass measurements. Anal. Chem. 76, 2511-2516. doi: 10.1021/ac03 55449

Conflict of Interest: The authors declare that the research was conducted in the absence of any commercial or financial relationships that could be construed as a potential conflict of interest.

Publisher's Note: All claims expressed in this article are solely those of the authors and do not necessarily represent those of their affiliated organizations, or those of the publisher, the editors and the reviewers. Any product that may be evaluated in this article, or claim that may be made by its manufacturer, is not guaranteed or endorsed by the publisher.

Copyright (C) 2021 Martineac, Vorobev, Moran and Medeiros. This is an openaccess article distributed under the terms of the Creative Commons Attribution License (CC BY). The use, distribution or reproduction in other forums is permitted, provided the original author(s) and the copyright owner(s) are credited and that the original publication in this journal is cited, in accordance with accepted academic practice. No use, distribution or reproduction is permitted which does not comply with these terms. 